\title{
NILAI-NILAI PROFETIK PEMBELAJARAN SASTRA ANAK DALAM FOLKLOR MAKASSAR ${ }^{1}$
}

\author{
Sitti Rabiah ${ }^{2}$ \\ Program Studi Bahasa dan Sastra Indonesia \\ Fakultas Sastra \\ Universitas Muslim Indonesia
}

\begin{abstract}
Abstrak
Revolusi mental sekarang ini marak menjadi pembicaraan beberapa pakar yang mengarah pada perubahan pola pikir mandiri dan berkepribadian dalam budaya. Terkait dengan hal tersebut, untuk melakukan perubahan secara cepat dan tepat maka kekuatan penggerak dapat diawali dengan memberi terobosan pada budaya daerah khususnya dalam pembelajaran sastra anak. Hal ini tentunya diyakini bahwa sastra anak dalam folklor Makassar dapat turut andil memberi kontribusi besar dalam dunia pendidikan sebagai langkah awal menjadikan generasi yang lebih baik. Dengan mengacu pada generasi "berkepribadian dalam budaya" bertujuan memperkokoh generasi penerus bangsa dalam menghadapi tantangan zaman melalui sastra anak karena memiliki pengaruh yang sangat besar bagi perkembangan karakter pribadi anak. Folklor Makassar berfungsi sebagai media yang efektif dalam menyalurkan sikap, ide atau gagasan, imajinasi, dan daya nalar yang terus ditumbuhkembangkan dari generasi ke generasi. Sastra anak dalam foklor Makassar sebagai salah satu kekayaan budaya mengandung nilai-nilai kehidupan yang dapat diwariskan secara turun temurun. Hal ini tentunya sesuai dengan nilai-nilai profetik guna membentuk manusia dengan pola pikir, sikap, dan tingkah laku yang berahklakul karimah. Pembelajaran sastra anak di sekolah dapat disajikan melalui materi cerita berbahasa Makassar dengan menyesuaikan tema setiap pelajaran dalam bentuk pengenalan sederhana yang disertai latihan untuk mengasah kemampuan analisis dalam memaknai dan mengetahui nilai-nilai moral. Cerita anak terkait keteladanan dan kisah-kisah pejuang Makassar dalam tokoh cerita anak dapat menginspirasi generasi muda dalam bertindak merupakan salah satu wujud pencapaian dari nilai-nilai profetik. Melalui pembelajaran tersebut menuntut pula daya kreatif seorang guru dalam menyesuaikan materi dan pengembangan kemampuan intelektual anak yang sesuai dengan perkembangan dan kemajuan IPTEK.
\end{abstract}

Kata Kunci: Nilai Profetik, Sastra Anak, dan Foklor.

\begin{abstract}
The mental revolution is now becoming the topic of several experts who lead to changes in the independent mindset and personality that reflects Indonesian culture. Related to this, to make quick and precise changes, the driving force can be initiated by giving a

\footnotetext{
${ }^{1}$ Makalah telah dipresentasikan dalam Seminar Internasional "Pengembangan Nilai-Nilai Profetik dalam Kehidupan Berbangsa melalui Bahasa, Sastra dan Pembelajarannya" yang diselenggarakan oleh Program Studi Pendidikan Bahasa dan Sastra Indonesia FKIP Universitas Muhammadiyah Malang pada 17-18 November 2015 di Malang, Indonesia.

2 (iD https:// orcid.org/ 0000-0002-1690-0025. Kontak penulis: sitti.rabiah@umi.ac.id / sittirabiah25@gmail.com
} 
breakthrough in regional culture, especially in children's literature learning development. It is certainly believed that children's literature in Makassar folklore can contribute to making a major contribution to the education sector as a first step in making a better generation. Referring to the generation of "personality that reflects Indonesian culture" aims to strengthen the nation's next generation in facing the challenges of the times through children's literature, because it has a huge influence on the development of children's personal character. Makassar folklore functions as an effective medium in channeling attitudes, ideas, imagination, and reasoning power that continues to be developed from generation to generation. Children's literature in Makassar's folklore as one of cultural assets contains life values that can be inherited from generation to generation. This is certainly in accordance with the prophetic values in order to shape human beings with a mindset, attitude, and good character. Learning children's literature in schools can be presented through Makassar language story material by adjusting the theme of each lesson in the form of a simple introduction accompanied by exercises to hone analytical skills in interpreting and knowing moral values. Children's stories related to exemplary and stories of Makassar heroes in children's characters can inspire the younger generation in acting is one manifestation of the achievement of prophetic values. Through this learning also demands the creativity of a teacher in adjusting the material and the development of children's intellectual abilities in accordance with the development and progress of science and technology.

Keywords: Prophetic Value, Children's Literature, Folklore

\section{PENDAHULUAN}

Revolusi mental sekarang ini marak menjadi pembicaraan beberapa pakar yang mengarah pada perubahan pola pikir mandiri dan berkepribadian dalam budaya. Sebuah perubahan yang diharapkan dapat menciptakan karakter bangsa yang kuat, memiliki kemandirian, kekuatan, berdaya saing serta kompetensi tinggi menghadapi kompetisi global yang kuat.

Terkait dengan hal tersebut, untuk melakukan perubahan secara cepat dan tepat maka kekuatan penggerak dapat diawali dengan memberi terobosan dalam dunia pendidikan. Institusi pendidikan memegang peranan penting dalam membentuk karakter bangsa yang kuat, salah satunya dengan melestarikan budaya daerah yakni mengenalkan sastra anak melalui pembelajaran di sekolah. Ketercapaian pembelajaran sastra dengan melibatkan unsur lain yakni memilih sastra anak dalam folklor Makassar sebagai arah perubahan yang berkelanjutan. Hal ini tentunya diyakini bahwa sastra anak dalam folklor Makassar dapat turut andil memberi kontribusi besar dalam dunia pendidikan sebagai langkah awal menjadikan generasi yang lebih baik.

Sastra daerah yang mencakup sastra anak dapat menjadi langkah awal dalam pengenalan budaya daerah lokal yang salah satunya dapat diperoleh dari folklor Makassar. Dengan pertimbangan bahwa usia anak-anak merupakan fase perkembangan yang sangat labil. Pada usia tersebut, anak-anak sangat mudah menerima berbagai hal, baik positif maupun negatif. Apa yang lebih banyak mereka terima pada usia anak-anak, 
akan sangat menentukan perkembangan intelektual maupun moral mereka pada saat dewasa nanti.

Dengan mengacu pada generasi "berkepribadian dalam budaya" yang bertujuan memperkokoh generasi penerus bangsa dalam menghadapi tantangan zaman dapat dimulai dengan mengangkat budaya daerah lokal melalui pembelajaran sastra anak. Folklor Makassar berfungsi sebagai media yang efektif dalam menyalurkan sikap, ide atau gagasan, imajinasi, dan daya nalar yang dapat terus ditumbuhkembangkan dari generasi ke generasi. Sastra anak dalam foklor Makassar sebagai salah satu kekayaan budaya mengandung nilai-nilai kehidupan yang dapat diwariskan secara turun temurun dengan memberikan nasihat dan penanaman etika sehingga pembaca dapat meneladani hal-hal positif.

Nilai-nilai kehidupan dalam folklor Makassar memiliki kesesuaian tujuan dengan kehadiran nilai-nilai profetik saat ini yakni membentuk manusia dengan pola pikir, sikap, dan tingkah laku yang berahklakul karimah. Nilai-nilai profetik dalam pembelajaran sastra anak di sekolah dapat disajikan melalui materi cerita berbahasa Makassar dengan menyesuaikan tema setiap pelajaran dalam bentuk pengenalan sederhana yang disertai latihan untuk mengasah kemampuan analisis dalam memaknai dan mengetahui nilai-nilai moral. Cerita anak terkait keteladanan dan kisah-kisah pejuang Makassar dalam tokoh cerita anak dapat menginspirasi generasi muda dalam bertindak merupakan salah satu wujud pencapaian dari nilai-nilai profetik. Melalui pembelajaran tersebut menuntut pula daya kreatif seorang guru dalam menyesuaikan materi dan pengembangan kemampuan intelektual anak yang sesuai dengan perkembangan dan kemajuan IPTEK.

Dengan landasan representasi nilai-nilai budaya yang diangkat dari tradisi dan etnik, tentunya memiliki peran dalam pembentukan pribadi peserta didik dengan tetap memerhatikan kebutuhan perkembangan anak. Anak-anak mulai belajar memproduksi atau mencari informasi maupun pengalamannya sendiri dari realitas kehidupan di sekelilingnya. Melalui sastra daerah, anak-anak dapat menumbuhkembangkan kesadaran dan kemampuan untuk membentuk sikap dalam masyarakat dan budaya yang majemuk. Pembelajaran sastra anak dapat pula memberi nilai ruang dalam mengembangkan tradisi dan realitas historis yang mulai punah sehingga dapat dijadikan sebagai jembatan untuk melatih dan membiasakan anak melestarikan budaya daerah.

\section{PEMBAHASAN}

\section{Pembelajaran Sastra Anak}

Pembelajaran sastra di sekolah pada dasarnya bertujuan membina apresiasi anak terhadap karya-karya sastra sehingga anak dapat mengembangkan kearifan, kejelian, dan ketelitian untuk menangkap isyarat-isyarat dalam kehidupan yang tercermin dalam karya sastra. Jika apresiasi telah tumbuh pada diri anak, maka akan memberikan dampak positif terhadap anak. Pembelajaran sastra anak dapat membantu perkembangan psikologi atau kejiwaan anak untuk lebih sensitif terhadap berbagai fenomena 
kehidupannya. Anak-anak yang biasa membaca sastra (bacaan anak), akan terbiasa turut merasakan dan melibatkan pikiran (imajinasi) sehingga seolah-olah dia yang mengalami peristiwa dalam karya yang dibacanya. Dengan begitu, imajinasi akan menumbuhkan pemikiran yang kritis dan kepekaan emosional yang tinggi dalam diri anak. Sastra mempunyai peranan penting dalam perkembangan kepribadian anak. Tokoh-tokoh dalam karya sastra secara tidak sadar akan mendorong atau mempengaruhi anak-anak mengendalikan berbagai emosi, misalnya: benci, cemas, takut, bangga, angkuh, sombong, dan lainnya. Pengajar dituntut kreatif dalam memilih bacaan untuk anak yang di dalamnya terdapat nasihat, nilai-nilai moral dalam membentuk karakter anak.

Pembelajaran sastra anak di sekolah dapat diklasifikasikan dalam tiga kelompok yakni pembelajaran fiksi, pembelajaran puisi, dan pembelajaran drama. Salah satu dari ketiga bagian tersebut yakni pembelajaran fiksi dapat disajikan pula melalui media dan materi folklor Makassar terkait dengan cerita rakyat. Dengan menjadikan folklor Makassar sebagai salah satu media pembelajaran sastra anak, pengajar dituntut kreatif memilih tokoh-tokoh pejuang Makassar yang telah berjuang dalam mempertahankan bangsa. Hal ini tentunya disesuaikan dengan kurikulum pembelajaran di sekolah sehingga ketercapaian pembelajaran dapat dicapai. Pemilihan cerita rakyat lokal menjadi pilihan dengan maksud menyajikan pembelajaran sastra anak yang efektif yakni terkait dengan tokoh-tokoh yang sering mereka dengarkan di sekelilingnya.

Pengajaran sastra di sekolah formal, terutama sastra Indonesia, sudah berlangsung sejak dahulu. Alasan pengajaran sastra di sekolah formal selalu mengalami perubahan sesuai dengan tuntutan zaman. Sejalan dengan perubahan zaman, pengajaran sastra sekarang memiliki berbagai alasan yang terkadang kompleks. Sekarang ini, pengajaran sastra di sekolah memiliki alasan yang beragam sesuai dengan perkembangan zaman dan tantangan dunia kerja yang akan dihadapi oleh para siswa. Dalam tataran global, sastra paling tidak memiliki peran ganda sebagai wahana pembekalan siswa untuk bersaing secara Internasional sekaligus sebagai identitas nasional dan bahkan lokal atau daerah.

\section{Pembelajaran Sastra Anak dalam Folklor Makassar}

Manusia yang hidup dalam budaya daerah akan menjaga perilakunya sesuai dengan budayanya. Latar belakang budaya daerah sangatlah didukung dengan adanya kebebasan berbicara dan kebebasan berdemokrasi dalam kehidupan bermasyarakat. Hal ini tentunya dapat menjadi acuan agar sastra daerah tetap menjadi kekayaan budaya yang dapat dikembangkan, karena tidak dapat dipungkiri bahwa sekarang ini mulai mengalami pergeseran pengaruh modernisasi. Pengembangan sastra daerah dapat dilakukan dengan memberi ruang sastra daerah dalam proses pembelajaran di sekolah. Melalui pembelajaran khususnya dalam mata pelajaran bahasa Indonesia tingkat SD dan SMP, berbagai sastra daerah anak dapat disajikan sebagai media maupun materi pembelajaran. Media dan materi pembelajaran tetap disesuaikan dengan kurikulum sekolah. 
Budaya bercerita kepada anak merupakan budaya yang universal, yaitu budaya yang turun temurun. Cerita-cerita yang disampaikan diupayakan jangan cerita yang ituitu saja. Dari cerita yang diberikan, si anak dapat memeroleh berbagai pendidikan, seperti sikap, moral, perbuatan baik, dan buruk. Maka dari itu guru harus mampu memilih cerita yang mengandung pesan moral, disiplin, yang dikemas dalam cerita anak dan sebisa mungkin menarik. Media cerita anak dalam folklor Makassar merupakan sebuah cerita yang mengungkapkan tentang peristiwa-peristiwa yang luar biasa atau gambaran yang bersifat historis atau gambaran tentang kehidupan masa lalu. Dalam cerita tersebut disajikan fakta sejarah yang diramu dengan imajinasi. Cerita fiksi historis haruslah didukung oleh penggambaran latar yang secara tepat dan meyakinkan sesuai dengan perkembangan kebudayaan yang ada. Misalnya: cerita rakyat "Lapong Pesokpesok na Lapong Buta-buta", cerita rakyat "Pau-paunna jinak akjanggoka" cerita perjuangan Sultan Hasanuddin, Sultan Alauddin, dan masih banyak lagi cerita rakyat lainnya.

Foklor Makassar yang berjudul "Lapong Pesok-pesok na Lapong Buta-buta" diceritakan persahabatan 2 orang anak yang lumpuh dan buta. Mereka menyadari keterbatasan dan kekurangannya. Bagi mereka cacat jasmani bukanlah suatu hambatan untuk mencapai sebuah cita-cita yang tinggi. Mereka ingin hidup serba berkecukupan dan tidak ingin lagi hidup di bawah bayang-bayang belas kasihan orang lain. Berbagai kalimat yang terdapat dalam cerita anak tersebut, tentunya menyampaikan amanat yang dapat menjadi penyemangat dan motivasi bagi setiap anak. Cerita anak tersebut menyampaikan dua hal pokok, berikut ini.

"Resopa siagang tambung ri karaeng naletei panngamaseang" (Hanya dengan kerja keras dan pasrah kepada Tuhan, maksud dan cita-cita akan tercapai).

"Assamaturuk kana laloko ri sekrea jama-jama ka taenamontu ansauruki nikanaya gauk assamaturuk" (Bersatulah di dalam menghadapi sesuatu pekerjaan karena tidak ada yang dapat mengalahkan perbuatan yang seperti itu).

Penggalan kalimat dalam cerita tersebut merupakan salah satu sastra daerah anak dalam folklor Makassar yang dapat membentuk karakter anak dalam mewujudkan citacita mereka melalui kerja keras, persatuan, dan gotong-royong. Bahkan, dalam agama selalu menganjurkan penganutnya untuk selalu bersatu dan saling mengajak kepada kebaikan. Hal tersebut tentunya dapat direalisasikan bagi anak dalam bekerja sama dalam diskusi kelompok maupun secara nyata mereka dapat saling mengingatkan tugastugas sekolah yang diberikan. Anak dapat pula saling mengingatkan dan mengajak untuk salat berjamaah sebagai wujud persatuan dan rasa kebersamaan.

Dalam cerita rakyat lainnya terdapat pula cerita yang berjudul "Pau-paunna jinak akjanggoka". Dikisahkan seorang abdi bernama I Basok yang tulus iklas menjalankan setiap perintah raja. Karena ketulusan hatinya di dalam menjalankan tugas, ia disenangi oleh raja dan sampai akhirnya ia ditawari apa saja yang diingini atau apa saja yang diminta, raja akan mengabulkannya. 
Attontong sako sikeddek Mulli, appabayang kalesako, rupa boddonnu Mulli, kallong mallerek lereknu, bukkuleng benrong-benronnu, karemeng tuntung lebbonnu, pakkaleang matippoknu. Mappiwalimi angkana, I Mulli Daeng Massayang tomattontonjak ia tamappabayang kaleak erok tongak ia, erok tongak makdik, pakalukak ri kallonnu, kaulangak ri ayaknu, kirua jammeng, kirua manaung butta, kirua makkambu kayu napara sayuk anrong tumallassukanta. (Menolehlah Mulli, tampakkanlah dirimu, wajah bundarmu, leher berjenjangmu, pinggang rampingmu, kulit kuning langsatmu, jari manismu. Menjawablah I Mulli Daeng Massayang, saya tak akan menolak dan tak akan memenuhi permintaanmu sebelum akan dibawa serta dalam peperangan. Karena itu, gantungkanlah aku di lehermu agar kita mati berdua, biarlah kedua orang tua kita bersedih, atas kematian kita berdua).

Penggalan cerita rakyat di atas menunjukkan nilai tanggung jawab yang besar dan kesadaran akan adanya rasa tanggung jawab yang memungkinkan suatu tugas dapat dilaksanakan dengan baik dan sepenuh hati. Tanpa kesadaran akan suatu tanggung jawab, mustahil seseorang dapat melaksanakan tugas dengan baik. Kesadaran akan tanggung jawab akan menimbulkan rasa solidaritas atau kesetiakawanan dan rela berkorban dalam bentuk apa saja demi suksesnya suatu tugas. Hal ini tentunya sangat dapat menjadi panutan bagi setiap anak karena pada saat tertentu pengorbanan diperlukan untuk mengemban suatu amanat yang diberikan.

Berdasarkan berbagai cerita rakyat di atas, maka dapat dikaitkan dengan pengajaran sastra di sekolah, pendekatan yang diterapkan kepada siswa tentu berbeda namun prinsipnya tetap sama. Karya sastra anak mencakup hikayat, dongeng, dan hikayat. Hal ini tentunya sangat ringan tetapi dibuat sedemikian menarik sehingga tidak seperti nasihat-nasihat yang membosankan. Dikaitkan dengan kurikulum yang membebaskan guru untuk memakai berbagai metode secara bervariasi dalam penyajian materi tertentu sehingga tujuan pembelajaran tercapai. Konsep dan teori sastra dan sejarah sastra harus dikurangi. Kegiatan pengajaran sastra harus difokuskan pada pengakraban siswa dengan karya sastra khususnya sastra anak dalam folklor Makassar sehingga siswa dapat menemukan keasyikan personal dalam membaca, mengkritik, dan mengkreasi teks terkait dengan latar budaya daerah sendiri. Penerapan multitafsir dalam mengapresiasi sastra harus dilakukan untuk menumbuhkan kreativitas siswa dalam mengapresiasi sastra daerah akan semakin berkembang.

\section{PENUTUP}

Dari karya sastra, orang akan belajar banyak tentang pengalaman hidup, persoalan dengan aneka ragamnya dan bagaimana menghadapinnya. Anak dapat belajar tatakrama/santun berbahasa dari pengungkapan kata-kata para sastrawan. Dengan demikian, karya sastra memudahkan guru dalam menanamkan pendidikan karakter terhadap anak, guna menjadikan anak yang sopan, santun di dalam lingkungan sekitarnya maupun di manapun mereka berada nantinya. Apabila karya sastra diajarkan sejak anak duduk dibangku SD, maka sejak dari dini ia dapat mengerti kehidupan 
manusia yang sederhana, berbudi luhur, dan disiplin sehingga menunjukkan nilai-nilai profetik yang terdapat dalam folklor Makassar. Hal itu dikarenakan di dalam sastra terdapat gambaran kebiasaan manusia bergaul dengan kebenaran, keindahan, dan kebaikan. Sastra dapat mengembangkan wawasan anak menjadi perilaku insani. Melalui karya sastra yang luas dapat membuat anak mengerti dunia. Pengajar mempunyai keleluasaan untuk menentukan bahan ajar bahasa dan sastra sesuai dengan kondisi lingkungan sekolah dan kemampuan peserta didik.

\section{REFERENCES}

Departemen Pendidikan dan Kebudayaan. Nilai-nilai Budaya dalam Susastra Daerah Sulawesi Selatan. Jakarta: Pusat Pembinaan dan Pengembangan Bahasa.

Sarumpet, Riris K Toha. 2010. Pedoman Penelitian Sastra Anak. Jakarta: Yayasan Pustaka Obor Indonesia.

Rabiah, Sitti. 2013. "Literature Contribution in Teaching of Indonesian Language as a Second Language for Preschool Children". Makalah. 4th Social, Development, and Environmental Studies International Conference 2013, Universiti Kebangsaan Malaysia. doi: 10.31227/osf.io/5m7td

Rabiah, Sitti. 2014. "Penanaman Nilai Karakter melalui Pembelajaran Sastra dalam Mata Kuliah Bahasa Indonesia di Perguruan Tinggi”. Makalah. Pertemuan Ilmiah Bahasa dan Sastra Indonesia XXXVI, Universitas Ahmad Dahlan. doi: 10.31227/osf.io/ktv9w

Rabiah, Sitti. 2014. "The Learning Model of Makassarese Language Based on the Character Building Concept: Research and Development in Elementary School of Makassar City" (Proceeding of International Seminar on Languages and Arts), Faculty of Languages and Arts, Universitas Negeri Padang. doi: 10.31227/osf.io/en63f 